\title{
Strain-dependent Differences in LTP and Hippocampus-dependent Memory in Inbred Mice
}

\author{
Peter V. Nguyen, ${ }^{1,5}$ Ted Abel, ${ }^{2}$ Eric R. Kandel,,${ }^{3,4}$ and Roussoudan Bourtchouladze ${ }^{3}$ \\ ${ }^{1}$ Department of Physiology and Division of Neuroscience, University of Alberta School of Medicine, Edmonton, Canada, T6G 2H7; \\ ${ }^{2}$ Department of Biology and Neuroscience Graduate Group, University of Pennsylvania, Philadelphia, Pennsylvania 19104 USA; \\ ${ }^{3}$ Center for Neurobiology and Behavior, and the ${ }^{4}$ Howard Hughes Medical Institute, College of Physicians \& Surgeons of Columbia University, \\ New York, New York 10032 USA
}

\begin{abstract}
Many studies have used "reverse" genetics to produce "knock-out" and transgenic mice to explore the roles of various molecules in long-term potentiation (LTP) and spatial memory. The existence of a variety of inbred strains of mice provides an additional way of exploring the genetic bases of learning and memory. We examined behavioral memory and LTP expression in area CA1 of hippocampal slices prepared from four different inbred strains of mice: C57BL/6J, CBA/J, DBA/2J, and 129/SvEms- $+{ }^{\text {Ter? }} / \mathrm{J}$. We found that LTP induced by four $100-\mathrm{Hz}$ trains of stimulation was robust and long-lasting in C57BL/6J and DBA/2J mice but decayed in CBA/J and $129 / \mathrm{SvEms}-+^{\text {Ter? }} / \mathrm{J}$ mice. LTP induced by one $100-\mathrm{Hz}$ train was significantly smaller after $1 \mathrm{hr}$ in the $129 /$ SvEms $-+{ }^{\text {Ter? }} / \mathrm{J}$ mice than in the other three strains. Theta-burst LTP was shorter lasting in $\mathrm{CBA} / \mathrm{J}, \mathrm{DBA} / 2 \mathrm{~J}$, and $129 / \mathrm{SvEms}-+^{\text {Ter? }} / \mathrm{J}$ mice than in C57BL/6J mice. We also observed specific memory deficits, among particular mouse strains, in spatial and nonspatial tests of hippocampus-dependent memory. $\mathrm{CBA} / \mathrm{J}$ mice showed defective learning in the Morris water maze, and both DBA/2J and CBA/J strains displayed deficient long-term memory in contextual and cued fear conditioning tests. Our findings provide strong support for a genetic basis for some forms of synaptic plasticity that are linked to behavioral long-term memory and suggest that genetic background can influence the electrophysiological and behavioral phenotypes observed in genetically modified mice generated for elucidating the molecular bases of learning, memory, and LTP.
\end{abstract}

Genetically modified mice have provided much data on the molecular mechanisms of learning and memory. These mice are useful for exploring the roles of specific signal transduction pathways in synaptic plasticity, on the one hand, and behavior, on the other (Chen and Tonegawa 1997; Mayford et al. 1995; Picciotto and Wickman 1998). A common methodologic approach used by numerous investigators is to correlate, in transgenic mice, behavioral performance on hippocampus-dependent tasks with hippocampal long-term potentiation (LTP), an activity-dependent enhancement of synaptic transmission that may underlie some forms of learning and memory in the mammalian brain (Bliss and Collingridge 1993). The production of transgenic mice often involves the use of two inbred strains: one supplies a viable background for breeding and survival and the other provides stem cells for genetic manipulation (Hogan et al. 1994). A potentially confounding factor in the interpretation of data obtained from genetically modified mice is the possibility that the behavioral and electrophysiologic phenotypes observed in these mice may be importantly influenced by genetic and phenotypic variation in the inbred strains used to construct the transgenic mouse model (Silva et al. 1997; Crawley et al. 1997; Gerlai 1996). This raises the

${ }^{5}$ Corresponding author.

E-MAIL erk5@columbia.edu; FAX (212) 543-5474. important question: How do the various wild-type mouse strains used in genetic experiments differ from each other in LTP and in memory storage?

A number of studies have identified electrophysiologic and behavioral differences between inbred mouse strains. An in vivo examination of synaptic plasticity in the dentate gyrus of various inbred strains has shown that, compared with $\mathrm{BL} / 6$ mice, transmission is enhanced in 129/Ola mice and maintenance of LTP is defective in DBA/2 mice (Bampton et al. 1999). The LTP deficit in DBA/2 mice has been correlated with lower expression of protein kinase C (PKC) in their hippocampi as compared with $\mathrm{C} 57 \mathrm{BL} / 6$ mice, which showed higher PKC levels and longer-lasting hippocampal LTP (Matsuyama et al. 1997). However, direct comparisons between the electrophysiologic studies of Bampton et al. (1999) and those of Matsuyama et al. (1997) are precluded because of the different LTP induction protocols used in the two studies and by the fact that Matsuyama et al. (1997) did not examine excitatory postsynaptic potential (EPSP) potentiation.

Behavioral experiments on $\mathrm{C} 57 \mathrm{BL} / 6$ and $\mathrm{DBA} / 2$ mice have emphasized differences between these two strains and have shown that DBA/2 mice may have impaired hippocampal function that compromises their performance on tasks requiring utilization of spatial and contextual informa-

LEARNING \& MEMORY 7:170-179 @ 2000 by Cold Spring Harbor Laboratory Press ISSN1072-0502/00 \$5.00

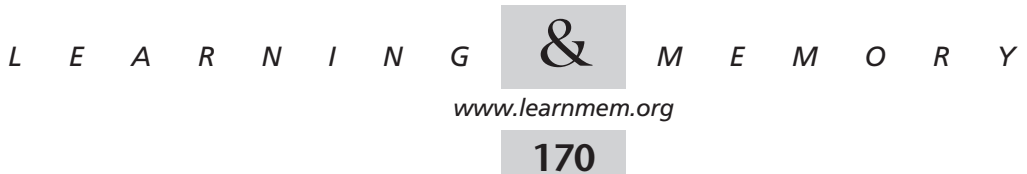


tion (Paylor et al. 1993). DBA/2 mice are impaired in spatial learning, as deminstrated by their poor performance in the eight-arm radial maze (Schwegler et al. 1990) and spontaneous alternation task (Bertholet and Crusio 1991). Some of these behavioral deficits may be correlated with reduced hippocampal PKC levels seen in DBA/2 mice as opposed to C57BL/6 mice (Wehner et al. 1990), but the exact neurobiologic basis for the observed behavioral deficits remains to be determined. Extensive behavioral studies have been performed to survey the performance of a variety of mouse strains in spatial and contextual learning and memory (e.g., Owen et al. 1997).

Overall, these data from separate behavioral and physiologic studies highlight the notion that specific strains of inbred mice may differ importantly in hippocampal LTP and in hippocampus-dependent behavioral tasks. The data clearly imply that selection of a strain in which to study the effects of genetic manipulations must be done with careful consideration of the known physiologic and behavioral phenotypes displayed by the strain. Thus, the electrophysiologic and behavioral characterization of numerous inbred strains is important for identifying those with phenotypes that may confound the interpretation of results derived from transgenic mice that are produced through the crossbreeding of these inbred strains.

An important methodological consideration that is further highlighted by these studies is the need to conjointly use multiple induction protocols for LTP and several behavioral tests involving spatial and nonspatial tasks, so that potentially subtle differences in synaptic plasticity and behavioral performance may be detected. It is a widely accepted fact that there are multiple forms of hippocampal LTP that can be induced by using different stimulation regimens, and a meaningful correlation between some forms of behavioral learning and memory and LTP may be possible only if specific types of behavioral memory are correlated with various forms of LTP. In the present study, we have used behavioral and electrophysiologic tests to probe for specific differences in distinct forms of hippocampal LTP and in spatial and nonspatial learning and memory among selected strains of inbred mice. These results have been published previously in abstract form (Abel et al. 1996).

\section{RESULTS}

\section{Basal Synaptic Physiology}

We examined synaptic input-output coupling in slices from the four strains of inbred mice and observed no significant differences between strains in the mean ratios of field EPSP (fEPSP) slope to presynaptic fiber volley amplitude. The mean ratio observed in $\mathrm{BL} / 6$ mice was $3.43 \pm 0.69(n=6$ slices, 5 mice). The lowest mean ratio was measured in $129 /$ SvEms mice $(2.40 \pm 0.41, n=5$ slices, 5 mice, $P>0.2)$, and the largest ratio was observed in CBA mice
(3.82 $\pm 0.89, n=5$ slices, 5 mice, $P>0.5)$. DBA $/ 2$ slices showed an intermediate ratio of $3.10 \pm 0.50(P>0.5, n=5$ slices).

\section{Paired-pulse Facilitation}

Paired-pulse facilitation ( $\mathrm{PPF}$ ) is a presynaptic enhancement of transmission in the second of two closely spaced stimuli (Katz and Miledi 1968). We found that PPF was significantly depressed in area CA1 of slices from DBA/2 mice. PPF was significantly reduced at interpulse intervals of $40 \mathrm{msec}$ (111 $\pm 3 \%, n=10, P<0.02$ for $\mathrm{BL} / 6$ comparison) and 100 msec $(111 \pm 4 \%, n=10, P>0.02)$. No significant differences in PPF between CBA, 129/SvEms, and BL/6 slices were observed (Table 1).

\section{LTP in the Schaffer Collateral Pathway}

LTP in area CA1 of the rodent hippocampus consists of early and late phases (reviewed in Huang et al. 1996), each with distinct induction requirements and biochemical signal transduction mechanisms (Abel et al. 1997; Bliss and Collingridge 1993; Frey et al. 1993; Huang and Kandel 1994; Nguyen et al. 1994; Nguyen and Kandel 1997). We examined the early phase of LTP in area CA1 of slices from the four strains of mice. In 129/SvEms mice, the mean level of potentiation seen $1 \mathrm{hr}$ after a single 1-sec duration train of $100 \mathrm{~Hz}$ of stimulation was $113 \% \pm 5$ of the pretetanization baseline level $(n=9)$. This was significantly lower than the corresponding value observed in BL/6 slices (144 $\pm 10 \%$, $n=9, P<0.01)$. For the CBA and DBA $/ 2$ strains, the average levels of potentiation at $1 \mathrm{hr}$ posttetanization were not significantly different from those of the BL/6 strain (CBA: $137 \pm 15 \%, n=7, \quad P>0.5 ; \quad \mathrm{DBA} / 2: \quad 144 \pm 15 \%, \quad n=10$, $P>0.5)$ (Fig. 1, one-train graphs). For longer-lasting forms of LTP, we examined LTP induced by two different stimulation protocols. Four successive $100-\mathrm{Hz}$ trains (1-sec duration, spaced 5 min apart) yielded a robust potentiation of fEPSPs in $\mathrm{BL} / 6(175 \pm 12 \%$ at $180 \mathrm{~min}$ posttetanization,

Table 1. Paired-pulse Facilitation

\begin{tabular}{|c|c|c|}
\hline Strain & $\begin{array}{c}\text { Interpulse } \\
\text { interval (ms) }\end{array}$ & $\begin{array}{c}\% \text { Facilitation }{ }^{a} \\
(n)\end{array}$ \\
\hline \multirow[t]{2}{*}{ C57BL/6J } & 40 & $129 \pm 6(15)$ \\
\hline & 100 & $138 \pm 10(15)$ \\
\hline \multirow[t]{2}{*}{$\mathrm{CBA} / \mathrm{J}$} & 40 & $127 \pm 4(12)$ \\
\hline & 100 & $131 \pm 5(12)$ \\
\hline \multirow[t]{2}{*}{$\mathrm{DBA} / 2 \mathrm{~J}$} & 40 & $111 \pm 3(10)^{*}$ \\
\hline & 100 & $111 \pm 3(10)^{*}$ \\
\hline \multirow[t]{2}{*}{ 129/SvEms-+ ${ }^{\text {Ter? }} / \mathrm{J}$} & 40 & $128 \pm 6(7)$ \\
\hline & 100 & $130 \pm 5(7)$ \\
\hline
\end{tabular}

${ }^{a} V$ alues are mean $\%$ facilitation \pm S.E.M.

$* P<0.02$ for comparison with $\mathrm{BL} / 6$ slices. All other values were not significantly different from $\mathrm{BL} / 6$ values. 
$n=10)$ and DBA/2 $(144 \pm 15 \%, 180$ min posttetanization, $n=10$ ) strains (Fig. 1, four-train graphs). By contrast, the levels of synaptic potentiation seen at $180 \mathrm{~min}$ posttetanization were significantly lower in $129 /$ SvEms slices $(105 \pm 8, n=11 \%, P<0.01)$ and in CBA slices $(123 \pm 10 \%$, $n=7, P<0.01)$ than in the $\mathrm{BL} / 6$ slices. With theta-burst stimulation (Fig. 1, theta-LTP graphs), robust and long-lasting LTP was observed in BL/6 slices $(170 \pm 8 \%, n=10)$ at $180 \mathrm{~min}$ posttetanization. In contrast, in the other three strains, the levels of potentiation at $3 \mathrm{hr}$ posttetanization were significantly depressed (CBA: $110 \pm 1 \%, n=6$, $P<0.01 ; \mathrm{DBA} / 2: 97 \pm 27 \%, n=6, P<0.01 ; 129 /$ SvEms: $100 \pm 18 \%, n=7, P<0.01$; see Fig. 1 ). In summary, the LTP data clearly indicate that deficits in the early and late phases of LTP exist among these specific inbred mouse strains and that the late phase in particular is susceptible to modulation by interstrain differences in genetic background (Table 2).

\section{Morris Water Maze}

Given that BL/6, CBA, DBA/2, and 129/SvEms strains show variable expression of LTP in the Schaffer collateral pathway, we asked the following questions: Is spatial learning affected in any of these inbred mouse strains? If spatial learning is altered, are the differences in Schaffer collateral LTP correlated with these alterations in spatial learning and memory? We first trained mice on the hidden-platform version of the Morris water maze task, which depends on the ability of the animal to learn and remember the relationships between multiple distal cues and the platform location (Morris et al. 1982). We found that escape latencies of $\mathrm{BL} / 6(n=12), \mathrm{DBA} / 2(n=17)$, and $129 /$ SvEms mice $(n=9)$, but not CBA mice $(n=8)$, significantly decreased during training (Fig. 2). In addition, BL/6 and 129/SvEms mice performed better than the DBA/ 2 mice on the Morris task.
129/SvEms/J and C57BL6/J
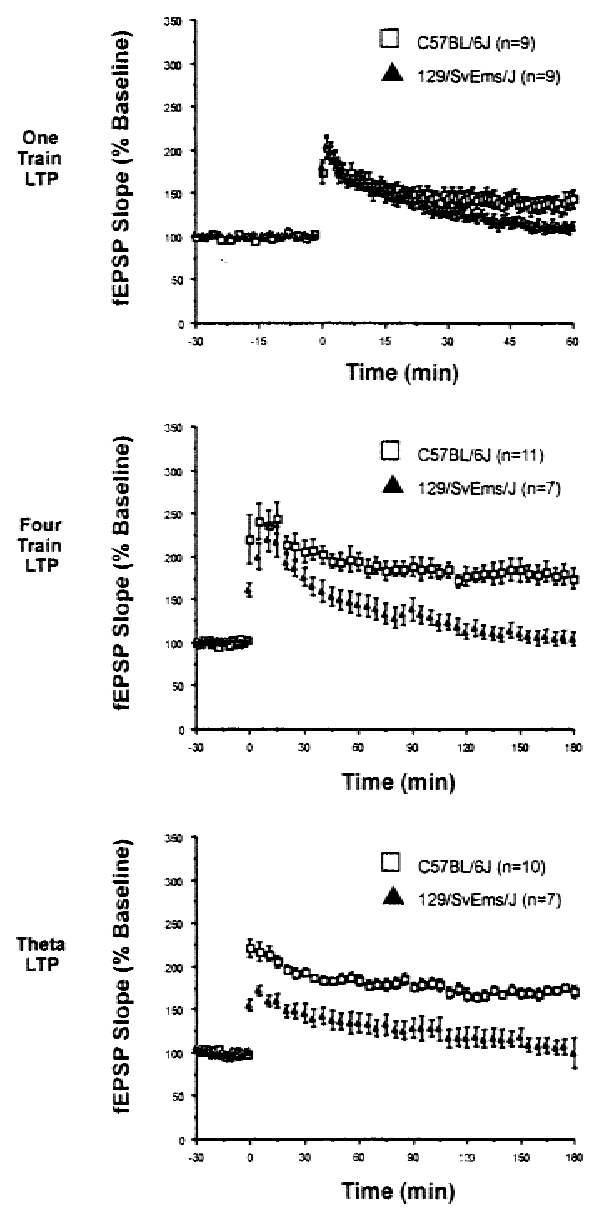

CBAJ and C57BL6/J
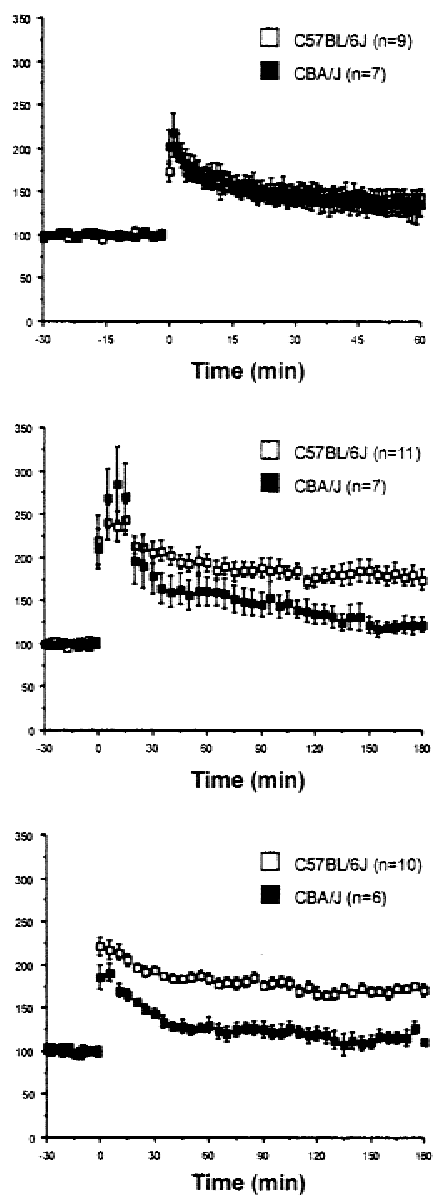

DBA/2J and C57BL6/J
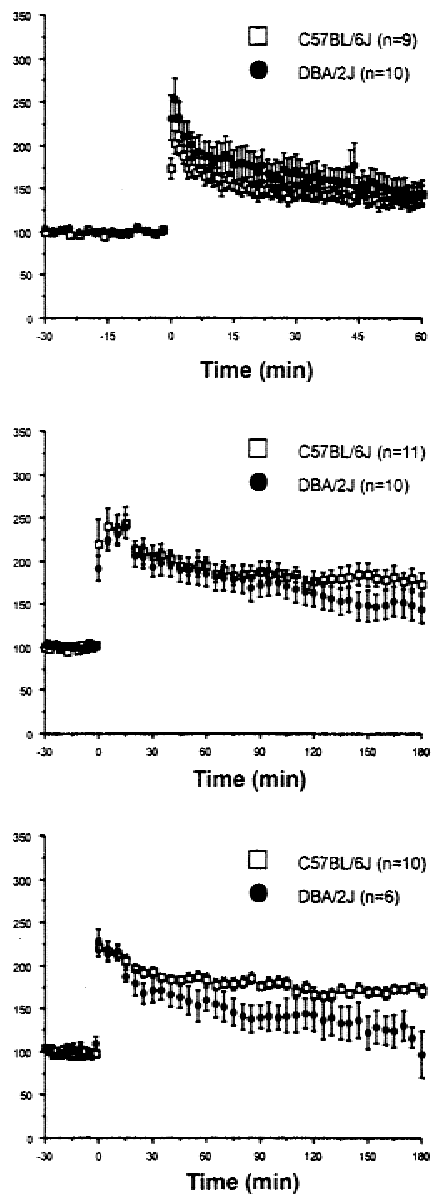

Figure 1 Expression of LTP in area CA1 is variable between different inbred mouse strains. The early and late phases of LTP showed significant differences in persistence in slices prepared from the four strains. One-train LTP (top) decayed more significantly at $1 \mathrm{hr}$ after tetanization in the 129/SvEms strain than in the other three strains. Four-train LTP (middle) was significantly reduced 3 hr after tetanization in the CBA and 129/SvEms strains. Theta-burst LTP (bottom) was significantly attenuated at $3 \mathrm{hr}$ posttetanization in all strains compared to $\mathrm{BL} / 6$ slices. For comparison, the same BL/6 LTP curve for each stimulation protocol is shown in each graph for the other three strains.

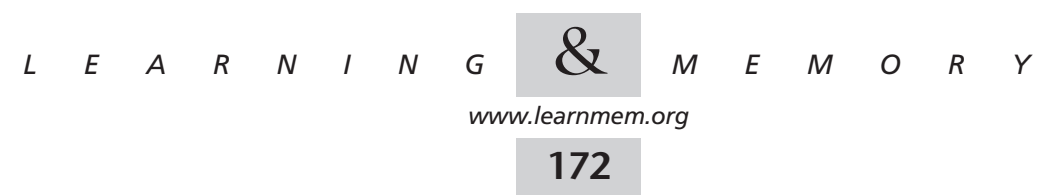




Table 2. Summary of LTP Data
\begin{tabular}{lllll}
\hline & C57BL/6J (n) & CBA/J (n) & DBA/2J $(n)$ & $129 / S v E m s / J ~(n)$ \\
\hline $1 \times 100 \mathrm{~Hz}(1 \mathrm{hr}$ posttetanization) & $144 \pm 10(9)$ & $137 \pm 15(7)$ & $144 \pm 15(10)$ & $113 \pm 5^{*}(9)$ \\
$4 \times 100 \mathrm{~Hz}(3 \mathrm{hr}$ posttetanization) & $175 \pm 12(10)$ & $123 \pm 10^{*}(7)$ & $144 \pm 15(10)$ & $105 \pm 8^{*}(11)$ \\
Theta LTP (3 hr posttetanization) & $170 \pm 8(10)$ & $110 \pm 1^{*}(6)$ & $97 \pm 27^{*}(6)$ & $100 \pm 18^{*}(7)$ \\
\hline Values are mean fEPSP slopes (\% of baseline) \pm S.E.M. & \\
$* P<0.05$ for comparison with BL/6 values. All other values were not significantly different from BL/6 values.
\end{tabular}

To assess spatial memory after acquisition of the hidden-platform task, we tested mice in a probe trial in which the platform was removed, and the mice were allowed to search for $1 \mathrm{~min}$. The time spent in each quadrant of the pool measures the spatial bias of a mouse's search pattern and is thought to correlate with explicit aspects of longterm spatial memory (Shenk and Morris 1985). BL/6 and $129 /$ SvEms mice searched selectively for the absent platform and spent significantly more time in the quadrant where the platform had been located during training than in the other three adjacent quadrants (Fig. $2 ; P<0.0001$ for both BL/6 and 129/SvEms mice). These mice also crossed the position of the platform significantly more often than the equivalent sites in the other three quadrants (TQ, AR, AL, OQ; $P<0.0001$ for both BL/ 6 and 129/SvEms mice; Fig. $2)$. The search pattern of $\mathrm{DBA} / 2$ mice was less selective than that for the BL/6 and 129/SvEms mice. Although DBA/2 mice spent significantly more time in the target quadrant than in the adjacent left or in opposite quadrants (TQ vs. AL, $P<0.001$; TQ vs. OQ, $P<0.0001$ ), the search times spent between the training quadrant and the adjacent right quadrant were not significantly different from each other (TQ vs. AR, $P=0.82$ ). The time spent in the training quadrant and the platform crossings for CBA mice were at chance level $(25 \pm 2.2 \%$ and $2.6 \pm 0.3$ for percentage of time and number of crossings in the training quadrant, respectively).

These differences in spatial memory could simply be due to poor vision, motor coordination, or motivation. To rule out a deficit in performance, we tested mice in the visible-platform version of the water maze. BL/6, 129/SvEms, and DBA/2 mice showed no differences in their latencies to find the platform in this version of the task $(\mathrm{df}=17$, $t=^{-} 0.302, P=0.77$ for $\mathrm{BL} / 6$ vs. DBA; $\mathrm{df}=12, t=0.36$, $P=0.72$ for BL6 vs. $129 / \mathrm{SvEms} ; \mathrm{df}=15, t=0.58, P=0.57$ for DBA vs. $129 /$ SvEms). The fact that DBA/2 mice performed well in the visible-platform task, which is hippocampus independent, suggests that $\mathrm{DBA} / 2$ mice have specific impairments in spatial memory but not in visual acuity, motivation to escape the water, or motor coordination. By contrast, CBA mice showed deficits in the visible task (df $=12, t={ }^{-} 2.82, P=0.02$ for $\mathrm{BL} / 6$ vs. $\mathrm{CBA} ; \mathrm{df}=15, t=2.97$, $P=0.01$ for CBA vs. DBA; $\mathrm{df}=10, t=2.59, P=0.03$ for CBA vs. 129/SvEms), suggesting that their spatial memory deficit might be due to a performance deficit. CBA mice swam the fastest, whereas $129 /$ SvEms mice swam the slowest $(24,15,21$, and $18 \mathrm{~cm} / \mathrm{sec}$ for CBA, 129/SvEms, BL/6, and DBA/2 mice, respectively). The CBA strain used in these studies carries the retinal degeneration $(r d)$ mutation, and we cannot rule out a deficit in visual acuity. However, a simple neurologic test of visual acuity did not reveal any deficit in vision in the CBA mice (R. Bourtchouladze, unpubl.).

\section{Barnes Circular Platform Maze}

To extend our studies of spatial memory in these inbred strains, we tested mice in the Barnes maze, a spatial memory task that requires hippocampal function (Barnes 1979; Barnes et al. 1994). Figure 3 shows that BL/6 mice $(n=7)$ excelled at locating an escape tunnel, whereas DBA/2 $(n=7)$ and CBA $(n=6)$ mice showed significantly poorer performance. $\mathrm{BL} / 6$ mice also performed better than $129 /$ SvEms mice $(n=8)$ on this test by taking more direct routes to the goal tunnel. However, this difference was not statistically significant. At the end of the training procedure, the maze was surrounded by curtains so that no extra maze cues were available. If the mice used a spatial representation of the surrounding environment in their search strategy, then they would be expected to shift back to a random or serial strategy, which would result in an increase in distance traveled to the tunnel. In this curtain test, there was a significant increase in distance for both BL/6 and 129/ SvEms mice $(P<0.01$ and 0.05 , respectively).

\section{Fear Conditioning}

In contextual and cued fear conditioning, mice learn to fear a new environment or an emotionally neutral conditioned stimulus (CS), such as a tone, because of its association with an aversive unconditioned stimulus (US), usually foot shock (Kim and Fanselow 1992; Phillips and LeDoux 1992). When exposed to the same context or the same CS, conditioned mice exhibit freezing behavior (Abel et al. 1997; Bourtchouladze et al. 1994, 1998). In addition to allowing good temporal resolution, these two forms of fear conditioning involve distinct neuroanatomic systems. Contextual conditioning is sensitive to lesions of the hippocampus and amygdala, whereas both cued and contextual fear conditioning are sensitive to lesions of only the amygdala (Frankland et al. 1998; Holland and Bouton 1999; Kim and Fanselow 1992; Kim et al. 1993; Phillips and LeDoux 1992).

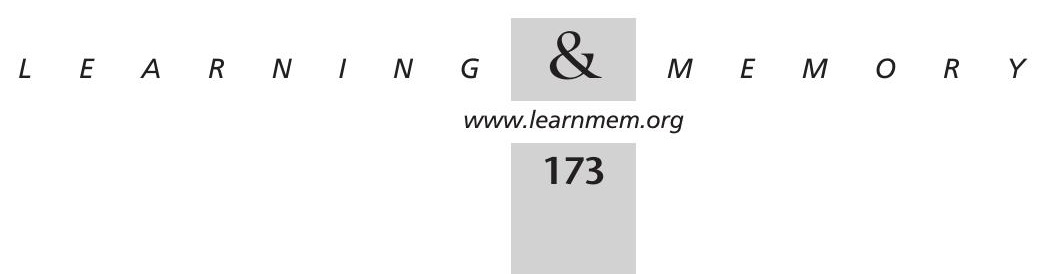




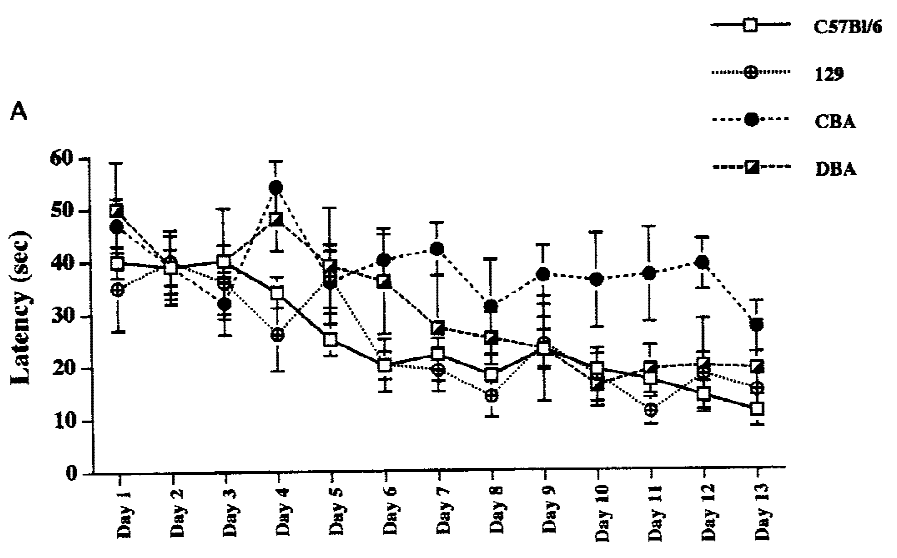

B

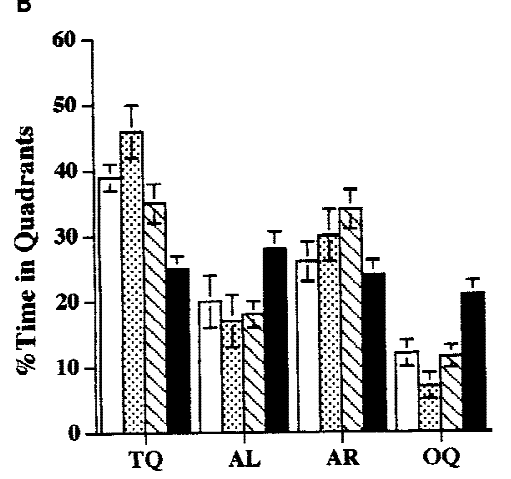

C

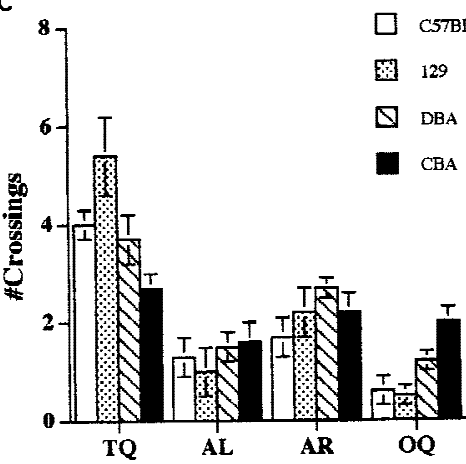

Figure 2 Performance of BL/6, DBA/2, CBA and 129/SvEms mice in the Morris wate maze task. (A) Mice were trained with one trial a day for 13 consecutive days in the hidden-platform version of the water maze. The average time to reach the platform (latency) is plotted versus trial day. BL/6, 129/SvEms, and DBA/2 mice improved significantly with training $(P<0.001)$, whereas CBA mice did not $(P>0.05)$. (B) The graph shows the results of a probe trial given on day 14,1 day after the completion of training. BL/ 6 and 129/SvEms mice spent significantly more time in the training quadrant (TQ) than in the adjacent quadrants to the left of TQ (TQ vs. AL, $F_{1,22}=3.62$, $P<0.001$ for $\mathrm{BL} / 6 ; F_{1,16}=4.39, P<0.001$ for $129 / \mathrm{SvEms}$ mice), to the right of TQ (TQ vs. $\mathrm{AR}, F_{1,22}=3.18, P<0.005$ for $\mathrm{BL} / 6 ; F_{1,16}=2.43, P<0.05$ for $129 / \mathrm{SvEms}$ mice), or opposite TQ (TQ vs. OQ, $F_{1,22}=8.26, P<0.0001$ for $\mathrm{BL} / 6 ; F_{1,16}=7.18$, $P<0.0001$ for $129 /$ SvEms mice). DBA $/ 2$ mice spent an equal amount of time in the TQ and the AR quadrants $\left(F_{1,32}=0.17, P>0.05\right)$ but spent significantly more time in the TQ than in the AL quadrant $\left(F_{1,32}=3.63, P<0.001\right)$ or in the $\mathrm{OQ}$ quadrant $\left(F_{1,32}=5.57, P<0.0001\right)$. CBA mice searched at chance levels in all four quadrants (TQ vs. AL, $F_{1,14}=0.09, P=0.34 ; \mathrm{TQ}$ vs. $\mathrm{AR}, F_{1,14}=0.07, P=0.93 ; \mathrm{TQ}$ vs. $\mathrm{OQ}$, $\left.F_{1,14}=2.06, P=0.05\right)$. (C) BL/6 and $129 /$ SvEms mice also crossed the exact site where the platform was located during training significantly more often than in the AR quadrant (TQ vs. AR, $F_{1,22}=3.18, P<0.005$ for $\mathrm{BL} / 6 ; F_{1,16}=3.10, P<0.005$ for $129 /$ SvEms mice), the $\mathrm{AL}$ quadrant (TQ vs. $\mathrm{AL}, F_{1,22}=3.10, P<0.005$ for $\mathrm{BL} / 6$; $F_{1,16}=4.28, P<0.0001$ for $129 /$ SvEms mice), or the OQ quadrant (TQ vs. OQ, $F_{1,22}=5.20, P<0.0001$ for $\mathrm{BL} / 6 ; F_{1,16}=5.43, P<0.0001$ for $129 /$ SvEms mice) . $\mathrm{DBA} / 2$ mice crossed the TQ and the AR quadrants a similar number of times $\left(F_{1,32}=1.54, P=0.13\right)$. However, $\mathrm{DBA} / 2$ mice crossed the equivalent sites in the $\mathrm{AL}$ $\left(F_{1,32}=3.71, P<0.001\right)$ and $\mathrm{OQ}\left(F_{1,32}=4.35, P<0.0001\right)$ quadrants fewer times. CBA mice crossed similarly in all four quadrants (TQ vs. AL, $F_{1,14}=2.04, P=0.32 ; \mathrm{TQ}$ vs. AR, $F_{1,14}=0.85, P=0.41$; TQ vs. OQ, $\left.F_{1,14}=0.78, P=0.44\right)$.

To assess memory for contextual conditioning, we tested mice in the same context $24 \mathrm{hr}$ after training (Fig. 4A). BL/6 $(n=7), \mathrm{DBA} / 2(n=7)$, and 129/SvEms $(n=7)$ mice showed similar levels of freezing immediately after training $(P>0.05)$. CBA mice $(n=5)$ froze significantly less than all other strains $(P<0.01$; data not shown), even though they jumped and vocalized after shock. When tested in the same context $24 \mathrm{hr}$ after training, BL/6 and 129/SvEms mice showed good retention and froze significantly more $(50.4 \pm 5 \%$ and $52.2 \pm 7.8 \%$, respectively) than did $\mathrm{DBA} / 2$ or $\mathrm{CBA}$ mice $(8.8 \pm 3 \%$ and $16.0 \pm 7.7 \%$, respectively; $P<0.001)$.

To test for cued conditioning, we measured freezing in response to a tone that had previously been paired with a foot shock. To avoid confounding effects of the training context, we tested mice in a novel context $24 \mathrm{hr}$ after training. Figure 4B shows that $\mathrm{BL} / 6$ and $129 /$ SvEms mice displayed robust fear conditioning and froze significantly more (40.2 $\pm 8 \%$ and $32.5 \pm 5 \%$, respectively) than did $\mathrm{DBA} / 2$ or CBA mice $(5.8 \pm 2 \%$ and $4.5 \pm 2 \%$, respectively; $P<0.001)$.

\section{DISCUSSION}

\section{Synaptic Function and Short-term Synaptic Plasticity in Inbred Mouse Strains}

Our tests of basal synaptic input-output coupling indicate that there are no significant differences in synaptic transmission in the Schaffer collateral pathway between any of the four strains examined. By contrast, PPF, a form of short-term plasticity believed to result from presynaptic enhancement of transmitter release (Katz and Miledi 1968), was impaired in the DBA/2 strain as compared with the BL/6 strain. Presynaptic calcium dynamics (calcium influx and sequestration) or synaptic vesicle proteins involved in mediating calcium-triggered vesicular release may be altered in CA3 presynaptic nerve terminals of slices from DBA/ 2 mice, so that the amount of calcium entering during a second, closely spaced stimulus pulse or the response to this calcium increase may be attenuated, leading to reduced PPF facilitation. Further research is needed to test this hypothesis.

\section{Variable Expression of LTP in Selected Inbred Mouse Strains}

The data presented in Fig. 1 and summarized in Table 2 show clearly that synaptic potentiation in the Schaffer collateral pathway in area CA1 can be robust or weak, depending on the particular mouse strain examined. BL/6 mice exhibited robust, long-lasting LTP induced by

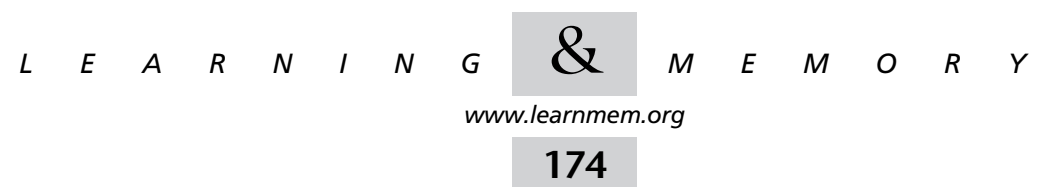




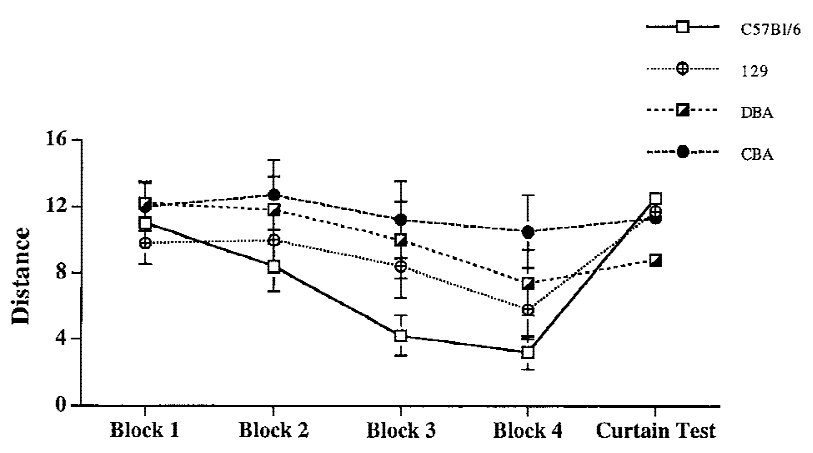

Figure 3 Performance of $\mathrm{BL} / 6, \mathrm{DBA} / 2, \mathrm{CBA}$, and 129/SvEms mice in the Barnes circular platform maze. The average distance from the goal tunnel was plotted versus blocks of days. There was no significant difference between BL/6, DBA/2, CBA, and 129/ SvEms mice in the first two blocks. However, BL/ 6 mice performed significantly better than CBA mice in locating the tunnel on the third $\left(F_{1,11}=2.94, P<0.01\right)$ and fourth $\left(F_{1,11}=3.25, P<0.01\right)$ blocks. Similarly, BL/6 mice were significantly better in locating the tunnel than $\mathrm{DBA} / 2$ mice on the third $\left(F_{1,12}=3.50, P<0.01\right)$ and fourth $\left(F_{1,11}=2.12, P<0.05\right)$ blocks. BL/6 mice were also significantly better in locating the tunnel than $129 /$ SvEms mice on the third block $\left(F_{1,13}=2.37, P<0.05\right)$. However, there was no significant difference on the fourth block $\left(F_{1,13}=1.85, P>0.05\right)$.

four-train and theta-burst stimulation protocols. These protocols have been shown to produce reliable late-phase LTP in slices from BL/6 mice (Abel et al. 1997; Nguyen and Kandel 1997). In other strains examined, such as CBA, $\mathrm{DBA} / 2$, and 129/SvEms, LTP was less robustly maintained after induction than in the $\mathrm{BL} / 6$ strain. The late phase decayed to pretetanization baseline fEPSP slope values in these non-BL/6 strains after theta-burst stimulation (Fig. 1), whereas LTP in CBA and 129/SvEms (but not in DBA/2) strains decayed to significantly lower values than LTP in the BL/6 strain after four-train stimulation. These data suggest that there may be a strong genetic basis for these forms of activity-dependent synaptic plasticity in the mammalian hippocampus. Furthermore, the results highlight the crucial influence that genetic background may exert on the physiologic phenotypes that are observed in studies using genetically modified mice to elucidate the molecular mechanisms of LTP. An interesting implication of these LTP comparisons between inbred strains is that $\mathrm{C} 57 \mathrm{BL} / 6 \mathrm{~J}$ mice may be the strain of choice for transgenic experiments designed to inhibit or attenuate LTP. By contrast, the other strains examined (CBA/J, DBA/2J, 129/SvEms-+ $\left.{ }^{\text {Ter? }} / \mathrm{J}\right)$ may be more suitable for transgenic experiments aimed at enhancing LTP.

\section{Spatial and Contextual Learning in Selected Inbred Mouse Strains}

The analysis of spatial behavior in both the water maze and the circular platform maze revealed a learning deficit for $\mathrm{CBA}$ and $\mathrm{DBA} / 2$ mice in comparison to $\mathrm{BL} / 6$ and 129/ SvEms mice. However, there was a difference in the learning deficit exhibited by the $\mathrm{CBA}$ and $\mathrm{DBA} / 2$ strains. Al- though CBA mice performed poorly in both spatial learning tasks, the performance of DBA/ 2 mice was only marginally impaired. For example, in the water maze, DBA/2 mice did search selectively in one-half of the pool and spent significantly less time in the opposite quadrant. Such findings suggest that DBA/2 mice may have been aware of the general location of the platform, but that they could not pinpoint it with the level of accuracy exhibited by BL/ 6 or $129 /$ SvEms mice. The poor performance of the DBA/ 2 mice suggests that they were unable to integrate distal cues into a precise spatial strategy, or that they were using nonspatial strategies based on responses to intra- or extramaze cues. In this respect, our findings are consistent with data reported by Upchurch and Wehner (1988). The neurochemical basis for the poor performance of the DBA2/J mice is likely to be polygenic and complex, but candidate mechanisms include reduced hippocampal PKC activity (Wehner et al. 1990), increased hippocampal cholinergic transmission (Albanese et al. 1985; Mandel et al. 1974), and altered morphology in hippocampal area CA3 (Schwegler et al. 1990).

BL/6 and 129/SvEms mice performed well in both spatial learning tasks. Interestingly, 129/SvEms mice were superior to BL/6 mice in the water maze task, but 129/SvEms mice performed more poorly than $\mathrm{BL} / 6$ mice in the Barnes circular platform maze. These differences between BL/6 and $129 /$ SvEms strains in two spatial memory tasks may be explained by different motivational demands of these tasks. Although both the water and Barnes mazes involve learning and remembering the relationship between extramaze cues
A

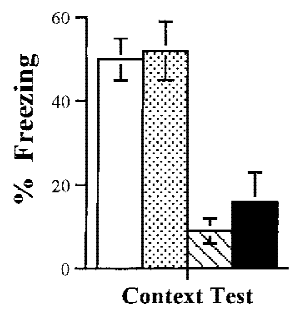

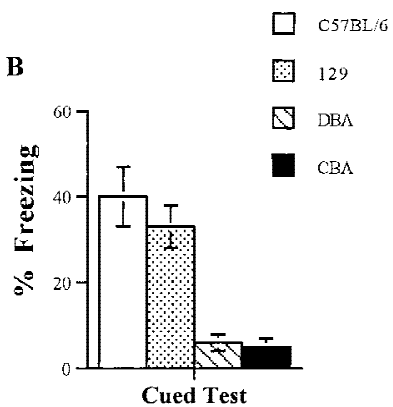

Cued Test
Figure 4 Performance of BL/6, DBA/2, CBA, and 129/SvEms mice in contextual and cued fear conditioning. (A) BL/6 and 129/ SvEms mice froze significantly more than DBA/2 or CBA mice when tested for contextual fear conditioning $24 \mathrm{hr}$ after training $\left(\mathrm{BL} / 6\right.$ vs. $\mathrm{DBA} / 2, \quad F_{1,12}=6.88, P<0.0001 ; \mathrm{BL} / 6$ vs. $\mathrm{CBA}$, $F_{1,10}=3.83, \quad P<001 ; \quad 129 /$ SvEms vs. DBA $/ 2, \quad F_{1,12}=5.13$, $P<0.001 ; 129 /$ SvEms vs. CBA, $\left.F_{1,10}=3.16, P<0.01\right)$. However, there was no significant difference in freezing responses between $\mathrm{BL} / 6$ and $129 / \mathrm{SvEms}$ mice $\left(F_{1,12}=0.19, P=0.84\right)$. (B) BL/6 and $129 /$ SvEms mice froze significantly more than DBA/2 or CBA mice when tested for cued fear conditioning $24 \mathrm{hr}$ after training (BL/6 vs. $\mathrm{DBA} / 2, \quad F_{1,12}=4.1, \quad P<0.001 ; \quad \mathrm{BL} / 6$ vs. $\mathrm{CBA}, \quad F_{1,10}=3.63$, $P<001 ; 129 /$ SvEms vs. DBA $/ 2, F_{1,12}=4.63, P<0.001 ; 129 /$ SvEms vs. CBA, $\left.F_{1,10}=4.18, P<0.001\right)$. However, there were no significant differences in freezing responses between $\mathrm{BL} / 6$ and $129 /$ SvEms mice $\left(F_{1,12}=0.78, P=0.44\right)$.

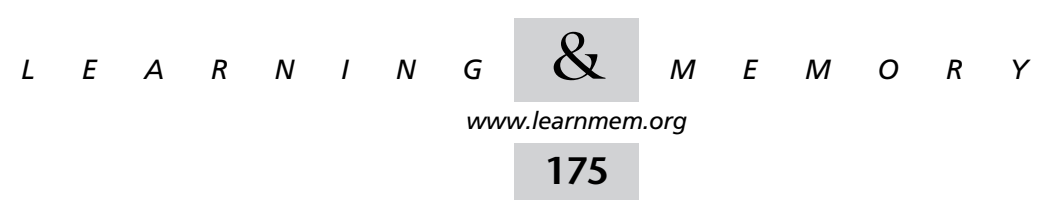


and the escape location, the Barnes maze is less aversive and may place fewer motivational demands than the water maze on some mouse strains. Indeed, additional analysis of these mice on hippocampus-dependent contextual learning task revealed no difference between these two strains of mice. BL/6 and 129/SvEms strains were also indistinguishable in cued-fear conditioning.

Recently, the possibility has been raised that the behavioral abnormalities seen in knockout mice might be due to differences in their genetic background rather than to a direct result of the targeted mutation (Silva et al. 1997; Gerlai 1996). This hypothesis was strengthened by the observation that mice from the 129 strain, which is the source of the embryonic stem (ES) cells used to generate knockout animals, exhibited behavioral abnormalities. However, behavioral performance in various 129 substrains appears to differ (Montkowski et al. 1997). For example, the 129/J substrain has substantial deficits in spatial learning and in the Porsolt forced-swim test. The 129/J mice also showed altered basal anxiety levels in the open field. The 129/Ola and $129 / \mathrm{Sv}$-ter/+ substrains performed normally in the water maze and the open-field tests. Other substrains, such as $129 / \mathrm{Sv}$ and 129/SvEv, are impaired in a T-maze alternation task, which is thought to reflect hippocampal function (Montkowski et al. 1997). Our behavioral findings on the 129/SvEms strain and other findings on 129 substrains suggest that genetic differences among 129 substrains are linked to their different performance levels in learning and memory. Because different ES cells are derived from a number of 129 substrains (Simpson et al. 1997), the effect of genetic background on the behavioral performance of genetically modified mice will differ depending on the line of ES cells used to generate the mutant mouse line.

We also found that both DBA/2 and CBA mice have deficits in contextual and cued fear conditioning tasks when mice were tested $24 \mathrm{hr}$ after training. Our findings of abnormal cued conditioning in DBA/2 mice contradict those reported by Paylor et al. (1994) who found that DBA/2 mice have deficits in contextual fear conditioning but not in cued fear conditioning. Importantly, DBA/ 2 mice exhibited normal contextual freezing responses immedi- ately after training. Differences between our results for DBA/2 mice and those of Paylor et al. (1994) and Owen et al. (1997) may be due to the sex of the mice used in these studies. We used exclusively male mice, and these were reported by Owen et al. (1997) to exhibit substantial impairments in fear conditioning relative to female mice. Further, differences in laboratory environment may also account for some of the observed differences in behavior (Crabbe et al. 1999).

At present, there is no precise neurochemical or neuroanatomic evidence that can account for the severe learning deficit observed in the CBA mice. However, the CBA strain carries the $r d$ gene that may result in poor visual acuity. In addition, in our hands, CBA mice were anxious and hyperactive, even after extensive handling. Such nervousness may also account for their failure in both hippocampus-dependent and hippocampus-independent tasks. Furthermore, the CBA strain is more aggressive than the BL/6 strain (Guillot et al. 1994). All of these factors may account for the poor performance of the CBA strain on these behavioral tests.

\section{Is There a Correlation Among Specific Forms of LTP and Learning and Memory Among Strains of Mice?}

Our data show that there is an apparent dissociation between some forms of hippocampal LTP and performance on some behavioral tasks among specific inbred mouse strains (Table 3). The 129/SvEms mice showed significant deficits in the maintenance of LTP induced by one and four trains of stimulation. These mice showed more rapidly decaying LTP than did BL/6 mice. The 129/SvEms mice also showed weaker theta-burst LTP than did BL/6 mice. Nevertheless both strains of mice were indistinguishable on their performances in cued and contextual conditioning, whereas 129/ SvEms mice performed more poorly than BL/6 mice in the Barnes circular platform maze. These results suggest that, at least for the 129/SvEms strain, the decay rate of hippocampal LTP may more closely correlate with behavioral performance in the Barnes maze than in cued and contextual conditioning paradigms, perhaps because cued condition-

Table 3. Summary of LTP and Behavioral Data for Selected Mouse Strains

\begin{tabular}{|c|c|c|c|c|c|c|c|}
\hline \multirow[b]{2}{*}{ Strains } & \multicolumn{3}{|c|}{ LTP maintenance } & \multicolumn{4}{|c|}{ Behavioral performance (memory) } \\
\hline & $\begin{array}{l}1 \times 100 \\
\mathrm{~Hz}\end{array}$ & $\begin{array}{c}4 \times 100 \\
\mathrm{~Hz}\end{array}$ & $\begin{array}{l}\text { Theta, } \\
3 \mathrm{sec}\end{array}$ & $\begin{array}{c}\text { Barnes } \\
\text { maze }\end{array}$ & $\begin{array}{l}\text { Morris } \\
\text { maze }\end{array}$ & $\begin{array}{c}\text { Cued } \\
\text { conditioning }\end{array}$ & $\begin{array}{l}\text { Contextual } \\
\text { conditioning }\end{array}$ \\
\hline C57BL/6J & + & + & + & + & + & + & + \\
\hline CBA/J & + & - & - & - & - & - & - \\
\hline DBA/2J & + & + & - & - & \pm & - & - \\
\hline 129/SvEms & - & - & - & - & + & + & + \\
\hline
\end{tabular}

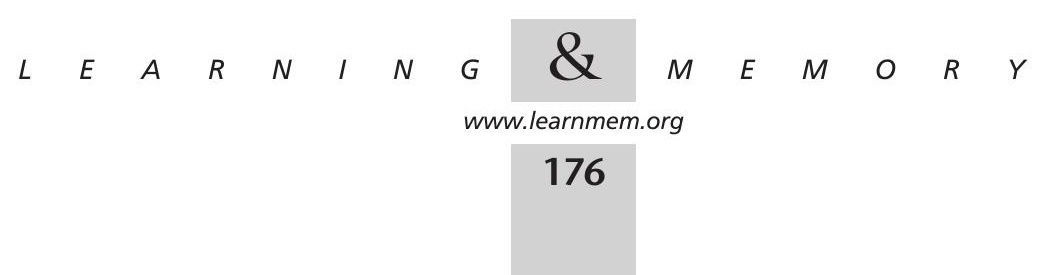


ing depends fully on the amygdala, whereas contextual conditioning is partly dependent on the amygdala. Other forms of synaptic modification, such as amygdaloid LTP, or synaptic plasticity in other regions of the hippocampus may be better correlated with the performance of 129/SvEms mice in the cued and contextual conditioning tasks.

In contrast, a distinct linkage between certain forms of hippocampal LTP and behavioral learning and memory is evident when the data from the CBA and DBA/ 2 mice are examined (Table 3). CBA mice showed significant impairments in learning and memory for spatial tasks (Morris and Barnes mazes) and for fear conditioning as compared with BL/6 mice. Compared with BL/6 mice, CBA mice showed normal LTP induced by one train of stimulation, whereas LTP induced by four trains and by theta-burst stimulation was impaired. This result suggests that the associative nature of these behavioral tasks may be linked to forms of hippocampal LTP that are induced by repeated application of successive trains of electrical stimulation. The poor performance of DBA/ 2 mice on a spatial task, such as the Barnes circular platform maze, and on nonspatial tasks, such as cued and contextual fear conditioning, correlates with a defective maintenance of theta-burst LTP but not with the normal maintenance observed for the other LTP protocols tested in the present study. LTP induced by theta-burst patterns of stimulation may be linked to exploratory behavior of rodents in spatially novel environments, and theta patterns of electrical activity in the hippocampus are known to occur during such exploratory behavior (Bland 1986; Larson et al. 1986; Otto et al. 1991). All of the tasks used in our studies place specific behavioral and cognitive demands on the animal, including spatial exploration and the formation of associations between spatial and nonspatial cues. The selective deficit in theta-burst LTP in DBA/2 mice and the observed defects in spatial learning in these mice suggest that theta-burst-induced forms of LTP may be more clearly linked to these cognitive impairments than other forms of hippocampal LTP in DBA/2 mice. Clearly, the analysis of LTP in additional mouse strains, particularly those with selective spatial or contextual learning deficits, will be required to explore the potential behavioral importance of theta-burst LTP.

\section{Perspective on Mouse Strains}

Our data demonstrate that learning, memory, and synaptic plasticity are significantly influenced by genetic background and by the specific behavioral tasks selected for examining learning and memory in these inbred strains of mice. The electrophysiological and behavioral phenotypes observed in genetically modified mice produced from some of these inbred strains (e.g., CBA and 129/SvEms) may be substantially influenced by the genetic backgrounds of these inbred strains of mice. As such, careful controls need to be used in studies aimed at elucidating the genetic and molecular mechanisms of complex, polygenic traits, such as learning and memory. Ideally, all behavioral and electrophysiological experiments should use identical inbred strains of mice, and the selection of strains for breeding and production of transgenic mice should be consistent with the overall objective of the experiment. Hence, if the objective is to genetically enbance spatial memory, then a strain with deficits in spatial term memory would be appropriate, provided that such impairments were not due to sensory or motor deficits. Conversely, if the goal of an experiment is to genetically disrupt spatial learning and memory, and LTP, then C57BL/ 6J mice would be an appropriate source strain because these mice showed robust LTP and intact spatial memory. Thus, our data underscore the need to examine the effects of a mutation on a variety of inbred backgrounds beyond the "conventional" BL/6 and 129 strains because of the diversity of phenotypes observed in mouse strains (Frankel 1998). Another approach to control for the effects of genetic background on phenotype is to perform studies in F1 hybrids between two inbred strains (Silva et al. 1997).

An issue of potential importance is the choice of behavioral task used to assay for deficits or improvements in behavioral learning and memory. It is clear that each behavioral task that is used in studies aimed at correlating hippocampal LTP with hippocampus-dependent memory should, ideally, place a burden on the hippocampus and not on other brain regions. Numerous tests exist for assaying spatial and nonspatial aspects of learning and memory, and these tests may differ from each other in the demand that each test imposes on hippocampal circuits in the intact animal. This notion and the fact that multiple forms of hippocampal LTP exist in the intact animal and in hippocampal slices highlight the potential complications that may arise when combining electrophysiological and behavioral approaches to look for correlations between LTP and some forms of memory. Different forms of hippocampal LTP, such as early and late LTP, may correlate with only certain forms of behavioral memory, and only a broad experimental strategy designed to examine many distinct types of synaptic potentiation and behavioral memory may reveal meaningful correlations between synaptic physiology and behavior.

\section{MATERIALS AND METHODS}

All experiments were performed on the following strains of inbred mice (Jackson Laboratories, Bar Harbor, ME): C57BL/6J, CBA/J, DBA/2J, and 129/SvEms- ${ }^{\text {Ter? }} / \mathrm{J}$. These are referred to as BL/6, CBA, $\mathrm{DBA} / 2$, and 129/SvEms throughout the article.

\section{Electrophysiology}

Transverse hippocampal slices ( $400 \mu \mathrm{m}$ thick) from 8- to 12 -weekold male mice were prepared using conventional procedures (Nguyen and Kandel 1997) and were maintained in an interface chamber at $28^{\circ} \mathrm{C}$. Slices were perfused at a flow rate of $1 \mathrm{ml} / \mathrm{min}$ with artificial cerebrospinal fluid (ACSF) bubbled with a gas mix-

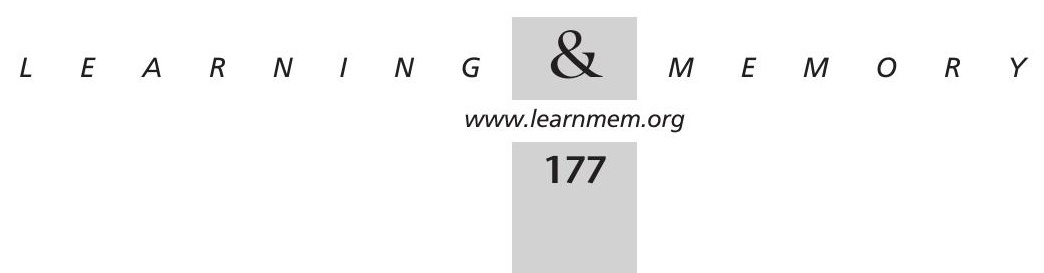


ture of $95 \% \mathrm{O}_{2}$ and $5 \% \mathrm{CO}_{2}$. The ionic composition of the ACSF was the same as that used by Nguyen and Kandel (1997). For all experiments, slices were allowed to recover for $90 \mathrm{~min}$ before recordings were initiated. A bipolar nickel-chromium stimulation electrode was positioned in the stratum radiatum layer of area CA1, and extracellular field EPSPs (fEPSPs) were recorded with a glass microelectrode (3-5-M $\Omega$ resistance) positioned in stratum radiatum. The stimulation intensity (0.08-msec pulse width) was adjusted to give fEPSP slopes approximately $40 \%$ of maximum evoked slopes, and baseline responses were elicited once per minute at this intensity. PPF of fEPSPs was tested in slices at this stimulation intensity by using interpulse intervals of 40 and $100 \mathrm{msec}$. As a measure of synaptic responsiveness, the fEPSP slope and corresponding presynaptic fiber volley amplitude were measured from fEPSP traces obtained at different stimulus strengths. Long-lasting LTP was induced by applying four 1-sec trains $(100 \mathrm{~Hz}$, test strength), spaced $5 \mathrm{~min}$ apart, to the stratum radiatum. In some experiments, the number of $100-\mathrm{Hz}$ trains was reduced to one to elicit short-lasting potentiation. We also used theta-burst stimulation, which consisted of 15 trains of 30-msec duration at $5 \mathrm{~Hz}$, with each train consisting of four pulses delivered at $100 \mathrm{~Hz}$ (i.e., a total of 60 pulses, Nguyen and Kandel 1997). Student's unpaired $t$-test was used to compare data obtained from different strains of mice. All values reported are means \pm S.E.M. .

\section{Morris Water Maze}

Water maze experiments were done as described previously (Abel et al. 1997; Bourtchouladze et al. 1994). After extensive handling, mice were tested in a water maze that was $1.2 \mathrm{~m}$ in diameter and filled with opaque water. On the first day of training, the mice were placed on the platform for $30 \mathrm{sec}$, and then they were allowed one 30 sec practice swim and one platform climb. They were allowed to rest for another $30 \mathrm{sec}$ on the platform, and then training was initiated. During training, the platform was not marked by any cue and remained in the same location, $0.7 \mathrm{~cm}$ below the surface of the water. The mice were trained with one trial per day for 13 days. Each swimming trial started with the mice facing the wall of the pool at a random position and ended when they climbed the platform. After reaching the platform, the mouse was allowed to remain on it for $30 \mathrm{sec}$. If mice did not find the platform within 60 sec, they were picked up by the experimenter and placed on the platform. In the probe test on day 14, the platform was removed. We analyzed the amount of time that the mice spent in each quadrant, the number of times the mice crossed the platform site (or similar locations in other quadrants), and swim speed. For both hidden- and visible-platform versions of the water maze, we used experimentally naive male mice $10-12$ weeks old. The mice were trained in three separate experiments, and each experiment included mice from each of the four strains. The experiments were recorded and analyzed using a tracking system (HVS-118, HVS Image, Hampton, UK).

\section{Barnes Circular Platform Maze}

Experimentally naive male mice $10-12$ weeks old were tested in the Barnes circular maze. The mice were trained in three separate experiments, and each experiment included mice from four strains. The Barnes circular maze was done as described previously (Huang et al. 1995). Briefly, the maze has 40 holes around the perimeter, one of which leads to a dark tunnel where the mouse can escape from bright light and aversive noise associated with the maze. The tunnel was always located beneath the same hole that was ran- domly determined for each mouse. The mice were tested with 1 trial per day for 20 days. We scored the distance by counting the number of holes between the first hole visited and the goal tunnel. Because the maze has 40 holes, the maximum distance possible was 20. The curtain test was given on day 21 . The maze was surrounded by white curtains so that no extramaze cues were available, and mice were allowed to search for the tunnel. The experiments were videotaped and analyzed.

\section{Fear Conditioning}

Fear conditioning experiments were performed as described previously (Abel et al. 1997; Bourtchouladze et al. 1994) by using male mice $10-12$ weeks old. On the training day, the mouse was placed in the conditioning chamber (Med Associates, St. Albans, VT) for 2 min before the onset of the CS, which lasted for $30 \mathrm{sec}$ at $2800 \mathrm{~Hz}$ and $85 \mathrm{~dB}$. The last $2 \mathrm{sec}$ of the CS was paired with the US, $0.7 \mathrm{~mA}$ of continuous foot shock. After an additional $30 \mathrm{sec}$ in the chamber, the mouse was returned to a home cage. Conditioning was assessed by scoring freezing behavior, which was defined as complete lack of movement, except for respiration, in intervals of $5 \mathrm{sec}$. Contextual conditioning was assessed for 5 consecutive min in the chamber in which the mice were trained. In cued conditioning experiments, the mice were placed in a novel context (another conditioning chamber with a smooth flat floor, posters on the wall, and a novel odorant) for 2 min (pre-CS test), after which they were exposed to the CS for $3 \mathrm{~min}$ (CS test). Mice were tested $24 \mathrm{hr}$ after training. For both contextual and cued conditioning experiments, the mice were trained in three separate experiments, and each experiment included mice from four strains. For all behavioral experiments, statistical comparisons were performed as described previously in Abel et al. (1997).

\section{ACKNOWLEDGMENTS}

We thank Newton Woo, Harriet Ayers, and Seta Izmirly for help in preparing the manuscript, and Nathaniel Berman and Irakli Gaprindashvili for help with the water maze experiments. This study was funded by a Medical Research Council of Canada Scholarship (PVN) and by grants from the Medical Research Council of Canada (PVN), the Alberta Heritage Foundation for Medical Research (PVN), the Whitehall Foundation (TA), the John Merck Fund (TA), the National Institutes of Health (TA; AG18199), and the Howard Hughes Medical Institute (ERK).

The publication costs of this article were defrayed in part by payment of page charges. This article must therefore be hereby marked "advertisement" in accordance with 18 USC section 1734 solely to indicate this fact.

\section{REFERENCES}

Abel, T., P.V. Nguyen, M. Barad, T.A.S. Deuel, E.R. Kandel, and R. Bourtchouladze. 1997. Genetic demonstration of a role for PKA in the late phase of LTP and in hippocampus-based long-term memory. Cell 88: 615-626.

Abel, T., P.V. Nguyen, R. Bourtchouladze, M.E. Bach, I. Gaprindashvili, P. Jain, and E.R. Kandel. 1996. Strain-dependent differences in hippocampal LTP and spatial memory. Soc. Neurosci. Abstr. 22: 1510.

Albanese, A., S. Gozzo, C. Iacopino, and M.C. Altavista. 1985. Strain-dependent variations in the number of forebrain cholinergic neurons. Brain Res. 334: 380-384.

Bampton, E.T., R.A. Gray, and C.H. Large. 1999. Electrophysiological characterisation of the dentate gyrus in five inbred strains of mouse Brain Res. 841: 123-134.

Barnes, C.A. 1979. Memory deficits associated with senescence: A neurophysiological and behavioral study in the rat. J. Comp. Physiol. Psychol. 93: 74-104. 
Barnes, C.A., M.W. Jung, B.L. McNaughton, D.L. Korol, K. Andreasson, and P.F. Worley. 1994. LTP saturation and spatial learning disruption: Effects of task variables and saturation levels. J. Neurosci. 14: 5793-5806.

Bertholet, J.Y. and W.E. Crusio. 1991. Spatial and non-spatial spontaneous alternation and hippocampal mossy fibre distribution in nine inbred mouse strains. Behav. Brain Res. 43: 197-202.

Bland, B.H. 1986. The physiology and pharmacology of hippocampal formation theta rhythms. Prog. Neurobiol. 26: 1-54.

Bliss, T.V. and G.L. Collingridge. 1993. A synaptic model of memory: Long-term potentiation in the hippocampus. Nature 361: 31-39.

Bourtchouladze, R., T. Abel, N. Berman, R. Gordon, K. Lapidus, and E.R. Kandel. 1998. Different training procedures for contextual memory in mice can recruit either one or two critical periods for memory consolidation that require protein synthesis and PKA. Learn. Mem. 5: 365-374.

Bourtchouladze, R., B. Frenguelli, J. Blendy, D. Cioffi, G. Schütz, and A.J Silva. 1994. Deficient long-term memory in mice with a targeted mutation of the cAMP-responsive element-binding protein. Cell 79: 59-68.

Chen, C. and S. Tonegawa. 1997. Analysis of synaptic plasticity and memory in the mammalian brain with the gene-knockout technology. In Long-term potentiation (ed. M. Baudry and J.L. Davis), pp. 55-69. The MIT Press, Cambridge, MA.

Crabbe, J.C., D. Wahlsten, and B.C. Dudek. 1999. Genetics of mouse behavior: Interactions with laboratory environment. Science 284: $1670-1672$

Crawley, J.N., J.K. Belknap, A. Collins, J.C. Crabbe, W. Frankel, N. Henderson, R.J. Hitzemann, S.C. Maxson, L.L. Miner, A.J. Silva, J.M. Wehner, A. Wynshaw-Boris, and R. Paylor. 1997. Behavioral phenotypes of inbred mouse strains: Implications and recommendations for molecular studies. Psychopharmacology (Berl.) 132: $107-124$

Frankel, W.N. 1998. Mouse strain backgrounds: More than black and white. Neuron 20: 183

Frankland, P.W., V. Cestari, R.K. Filipkowski, R.J. McDonald, and A.J. Silva. 1998. The dorsal hippocampus is essential for context discrimination but not for contextual conditioning. Behav. Neurosci. 112: 863-874

Frey, U., Y.-Y. Huang, and E.R. Kandel. 1993. Effects of cAMP simulate a late stage of LTP in hippocampal CA1 neurons. Science 260: 1661-1664

Gerlai, R. 1996. Gene-targeting studies of mammalian behavior: Is it the mutation or the background genotype? Trends Neurosci. 19: 177-181.

Guillot, P.V., P.L. Roubertoux, and W.E. Crusio. 1994. Hippocampal mossy fiber distributions and intermale aggression in seven inbred mouse strains. Brain Res. 660: 167-169.

Hogan, B., R. Beddington, F. Costantini, and E. Lacy. 1994. Manipulating the mouse embryo, $2^{\text {nd }}$ ed. Cold Spring Harbor Laboratory Press, Cold Spring Harbor, NY.

Holland, P.C. and M.E. Bouton. 1999. Hippocampus and context in classical conditioning. Curr. Opin. Neurobiol. 9: 195-202.

Huang, Y.-Y. and E.R. Kandel. 1994. Recruitment of long-lasting and protein kinase A-dependent long-term potentiation in the CA1 region of hippocampus requires repeated tetanization. Learn. Mem. 1: 74-82.

Huang, Y.-Y., E.R. Kandel, L. Varshavsky, E.P. Brandon, M. Qi, R.L. Idzerda, G.S. McKnight, and R. Bourtchouladze. 1995. A genetic test of the effect of mutations in PKA on mossy fiber LTP and its relation to spatial and contextual learning. Cell 83: 1211-1222.

Huang, Y.-Y., P.V. Nguyen, T. Abel, and E.R. Kandel. 1996. Long-lasting forms of synaptic potentiation in the mammalian hippocampus. Learn. Mem. 3: 74-85.

Katz, B. and R. Miledi. 1968. The role of calcium in neuromuscular facilitation. J. Physiol. (Lond.) 195: 481-492.

Kim, J.J. and M.S. Fanselow. 1992. Modality-specific retrograde amnesia of fear. Science 256: 675-677.

Kim, J.J., R.A. Rison, and M.S. Fanselow. 1993. Effects of amygdala, hippocampus and periaqueductal gray lesions on short- and long-term contextual fear. Behav. Neurosci. 107: 1093-1098.
Larson, J., D. Wong, and G. Lynch. 1986. Patterned stimulation at the theta frequency is optimal for the induction of hippocampal long-term potentiation. Brain Res. 368: 347-350.

Mandel, P., G. Ayad, J.C. Hermetet, and A. Ebel. 1974. Correlation between choline acetyltransferase activity and learning ability in different mutant mice strains and their offspring. Brain Res. 72: $65-70$.

Matsuyama, S., U. Namgung, and A. Routtenberg. 1997. Long-term potentiation persistence greater in $\mathrm{C} 57 \mathrm{BL} / 6$ than $\mathrm{DBA} / 2$ mice: Predicted on basis of protein kinase $\mathrm{C}$ levels and learning performance. Brain Res. 763: 127-130.

Mayford, M., T. Abel, and E.R. Kandel. 1995. Transgenic approaches to cognition. Curr. Opin. Neurobiol. 5: 141-148.

Montkowski, A., M. Poettig, A. Mederer, and F. Holsboer. 1997. Behavioural performance in three substrains of mouse strain 129 Brain Res. 762: 12-18.

Morris, R.G.M., P. Garrud, J.N.P. Rawlins, and J. O'Keefe. 1982. Place navigation impaired in rats with hippocampal lesions. Nature 297: 681-683.

Nguyen, P.V., T. Abel, and E.R. Kandel. 1994. Requirement for a critical period of transcription for induction of a late phase of LTP. Science 265: 1104-1107.

Nguyen, P.V. and E.R. Kandel. 1997. Brief $\theta$-burst stimulation induces a transcriptionally dependent late phase of LTP requiring cAMP in area CA1 of mouse hippocampus. Learn. Mem. 4: 230-243.

Otto, T., H. Eichenbaum, S.I. Wiener, and C.G. Wible. 1991. Learning-related patterns of CA1 spike trains parallel stimulation parameters optimal for inducing hippocampal long-term potentiation. Hippocampus 1: 181-192.

Owen, E.H., S.F. Logue, D.L. Rasmussen, and J.M. Wehner. 1997. Assessment of learning by the Morris water task and fear conditioning in inbred mouse strains and F1 hybrids: Implications of genetic background for single gene mutations and quantitative trait loci analyses. Neuroscience 80: 1087-1099.

Paylor, R., L. Baskall, and J.M. Wehner. 1993. Behavioral dissociations between C57BL/6 and DBA/2 mice on learning and memory tasks: A hippocampal dysfunction hypothesis. Psychobiology 21: 11-26.

Paylor, R., R. Tracy, J. Wehner, and J.W. Rudy. 1994. DBA/2 and C57BL/6 mice differ in contextual fear but not auditory fear conditioning. Behav. Neurosci. 108: 810-817.

Phillips, R.G. and J.E. LeDoux. 1992. Differential contribution of amygdala and hippocampus to cued and contextual fear conditioning. Behav. Neurosci. 106: 274-285.

Picciotto, M.R. and K. Wickman. 1998. Using knockout and transgenic mice to study neurophysiology and behavior. Physiol. Rev. 78: 1131-1163.

Schwegler, H., W.E. Crusio, and I. Brust. 1990. Hippocampal mossy fibers and radial-maze learning in the mouse: A correlation with spatial working memory but not with non-spatial reference memory. Neuroscience 34: 293-298.

Shenk, F. and R.G.M. Morris. 1985. Dissociation between the components of spatial memory in rats after recovery from the effects of retrohippocampal lesion. Exp. Brain. Res. 58: 11-28.

Silva, A., et al. 1997. Mutant mice and neuroscience: Recommendations concerning genetic background. Banbury Conference on Genetic Background in Mice. Neuron 19: 755-759.

Simpson, E.M., C.C. Linder, E.E. Sargent, M.T. Davisson, L.E. Mobraaten, and J.J. Sharp. 1997. Genetic variation among 129 substrains and its importance for targeted mutagenesis in mice. Nat. Genet. 16: 19-27.

Upchurch, M. and J.M. Wehner. 1988. Differences between inbred strains of mice in Morris water maze performance. Behav. Genet. 18: 55-68.

Wehner, J.M., S. Sleight, and M. Upchurch. 1990. Hippocampal protein kinase $\mathrm{C}$ activity is reduced in poor spatial learners. Brain Res. 523: $181-187$

Received March 17, 2000; accepted in revised form April 12, 2000.

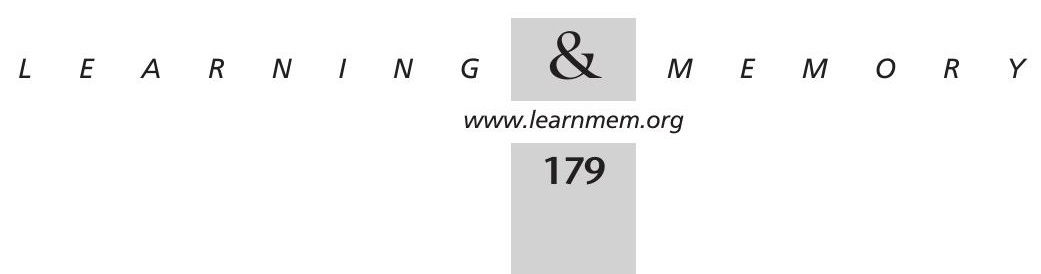




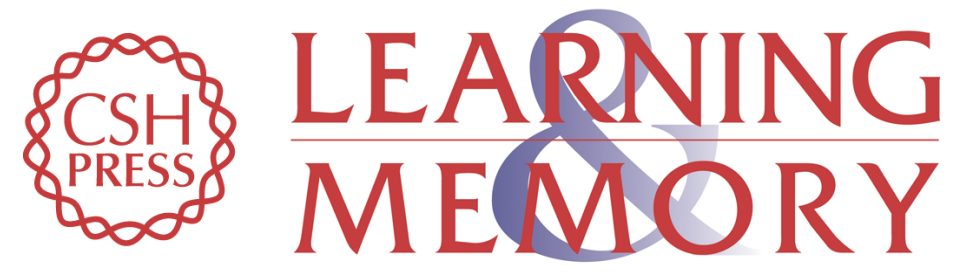

\section{Strain-dependent Differences in LTP and Hippocampus-dependent Memory in Inbred Mice}

Peter V. Nguyen, Ted Abel, Eric R. Kandel, et al.

Learn. Mem. 2000, 7:

Access the most recent version at doi:10.1101//m.7.3.170

References This article cites 45 articles, 9 of which can be accessed free at: http://learnmem.cshlp.org/content/7/3/170.full.html\#ref-list-1

License

Email Alerting Receive free email alerts when new articles cite this article - sign up in the box at the Service top right corner of the article or click here. 